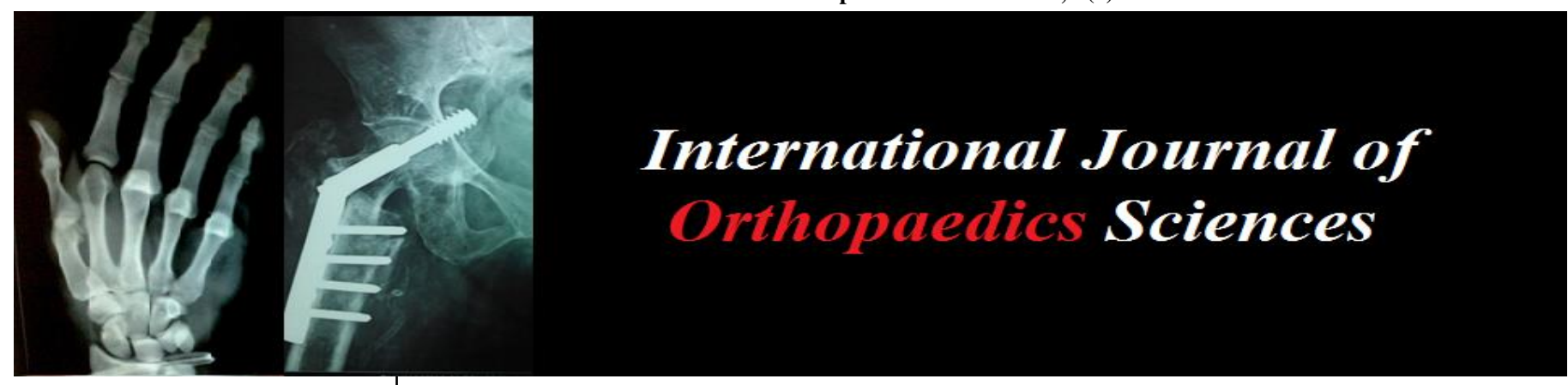

E-ISSN: 2395-1958

P-ISSN: 2706-6630

IJOS 2020; 6(1): 475-479

(C) 2020 IJOS

www.orthopaper.com

Received: 09-11-2019

Accepted: 13-12-2019

Dr. Santosh Kumar Sahu Assistant Professor of

Orthopaedics, IMS \& SUM

Hospital, Bhubaneswar, Odisha,

India

Dr. Deepak Verma

PGT, Dept. of Orthopaedics,

IMS\&SUM Hospital,

Bhubaneswar, Odisha, India

Corresponding Author:

Dr. Santosh Kumar Sahu

Assistant Professor of

Orthopaedics, IMS \& SUM

Hospital, Bhubaneswar, Odisha,

India

\section{Primary shoulder hemiarthroplasty in the management of post traumatic proximal humerus fractures}

\section{Dr. Santosh Kumar Sahu and Dr. Deepak Verma}

DOI: https://doi.org/10.22271/ortho.2020.v6.i1i.1910

\section{Abstract}

Proximal humerus fractures are fairly common, with overall incidence being $4-5 \%$ of all fractures. Displaced four-part proximal humerus fractures often pose challenges before the surgeon especially in the elderly. Depending on the mechanism of injury and bone density at the time of injury, fracture patterns vary. In the older population, these fractures occur often in association with osteoporosis, preexisting rotator cuff pathology, and other comorbidities. These fractures are associated with a risk of avascular necrosis of the humeral head, with an incidence ranging from $21 \%$ to $75 \%$. Shoulder hemiarthroplasty and, reverse total shoulder arthroplasty (RTSA) are indicated for complex fractures with high complication rates following head preserving procedures. The present study aims to assess the functional outcome of shoulder hemiarthroplasty in patients diagnosed with four part fracture and four part fracture dislocation admitted in Orthopaedic Department of IMS \& SUM Hospital, Bhubaneswar in terms of pain, shoulder stability and range of movements at shoulder joint.

Keywords: Proximal humerus, hemiarthroplasty, pimary, post traumatic

\section{Introduction}

Proximal humerus is second most common fracture site in the upper limb, most common being the distal radius. Incidence is about $4-5 \%$ of all fractures and greater than $70 \%$ of all proximal humeral fractures occur in patients over 60 years ${ }^{[1-3]}$. Four-part fractures of proximal humerus and fracture-dislocations account for only $5 \%$ of all proximal humerus fractures ${ }^{[4]}$. Displaced four-part proximal humerus fractures often pose challenges before the surgeon especially in the elderly. Depending on the mechanism of injury and bone density at the time of injury, fracture patterns vary. In the older population, these fractures occur often in association with osteoporosis, preexisting rotator cuff pathology, and other comorbidities. These fractures are associated with a risk of avascular necrosis of the humeral head, with an incidence ranging from $21 \%$ to $75 \%$. ${ }^{[11,12,14,15]}$. While most of the undis placed fractures, can be managed non operatively ${ }^{[1-3]}$, the treatment of displaced fractures is still continues to be a matter of debate. With recent advances in the techniques and implants such as PHILOS system, surgical fixation of proximal humerus fractures has gained momentum among orthopods. However, the rates complications in head preserving procedures appears to be high, especially the rate of avascular necrosis (AVN) remains fairly high even with the most modern implants. The prevalence of AVN following proximal humerus fractures increases over time ${ }^{[3]}$ Humeral head split and complex three- and four-part fractures are at higher risk for the development of malunion and AVN following internal fixation ${ }^{[5,6]}$. Shoulder hemiarthroplasty and, reverse total shoulder arthroplasty (RTSA) are indicated for complex fractures with high complication rates following head preserving procedures. Joint replacement has limited indications, strict selection of patients, and significant in vasivity, but faster active recovery [4, 5]. Hemiarthroplasty for the management of displaced three or four-part fractures was initially reported by Neer ${ }^{[15]}$. Several studies have reported inconsistent results as regards ROM and functional outcome ${ }^{[2-4,7-10,13]}$

\section{Objectives}

The present study aims to assess the functional outcome of shoulder hemiarthroplasty in patients diagnosed with four part fracture and four part fracture dislocation admitted in 
Orthopaedic Department of IMS \& SUM Hospital, Bhubaneswar from July 2015 to June 2019 in terms of pain, shoulder stability and range of movements at shoulder joint.

\section{Methodology}

It was a retrospective study conducted at IMS\&SUM Hospital, Bhubaneswar during the period of July 2015 to June 2019. A total of 30 Patients diagnosed with four part proximal humerus fractures based on Neer's classification, fracture involving greater than $40 \%$ of the articular surface, Head splitting fractures, 3-part, 4-part fracture-dislocations in elderly patients with osteoporotic bone, fractures that are not reconstructable by osteosynthesis and age $>60 \mathrm{yrs}$, presenting at the Department of Orthopaedics, IMS\&SUM Hospital, Bhubaneswar were included in the study. All patients with undisplaced proximal humeus fractures, pathological fractures and those with compound fractures with or without neurovascular deficit were excluded from the study.

Surgical Procedure: Patients were treated with shoulder hemi arthroplasty surgery. A modular prosthesis (Depuy Global Fx System) was used with a stem 130-mm long and 8 mm thick for 7 patients; and 12 received stem size of $140 \mathrm{~mm}$ long and $10 \mathrm{~mm}$ thick size. The humeral head used for final implantation had a thickness one size less or equal to the extracted humeral head and included 46x18 mm, 46x15 mm, $40 \times 18 \mathrm{~mm}$, and $40 \times 15 \mathrm{~mm}$. Patients were placed in the a semi-Fowler beach chair position. For all cases, standard deltopectoral approach was used. The cephalic vein was identified and retracted laterally with the deltoid fibers. The short head of biceps and the coracobrachialis muscle were displaced medially to gain access into the anterior aspect of shoulder joint. The arm was externally rotated to stretch the subscapularis muscle, which lies beneath the conjoint tendon. A blunt instrument was passed between the capsule and the subscapularis muscle, then the subscapularis tendon was divided from insertion onto to the lesser tuberosity of humerus, leaving behind a small strip for future repair. The capsule was incised longitudinally to enter the joint. The biceps tendon is a very important landmark to identify the interval between the lesser and greater tuberosity. A pair of scissors were passed into the sheath of biceps tendon and the transverse humeral ligament was divided. The axillary nerve can be palpated by passing the volar surface of index finger down along the anterior surface of the subscapularis muscle. Scofield-type retractor was used to retract and protect the nerve during head extraction. The greater and lesser tuberosities retracted out of the way by traction sutures, and the fractured humeral head was retrieved and measured for height and diameter using the Humeral Head Template. After selection of the humeral head component, cancellous graft from the head was collected, which was used for secure tuberosity fixation. Humeral shaft was delivered up and out of the wound and with the help of rongeurs the sharp corners of the shaft was trimmed and bone fragments along with blood clots from the humeral shaft canal was removed. Medullary canal was prepared by serial reaming $(6-12 \mathrm{~mm})$. With the proper size trial head attached to a trial stem, was placed into the intramedullary canal, with elbow in 90-degree flexion and parallel to the floor and in zero degree rotation. A gentle traction was then applied and the trial stem was lifted till the level of glenoid fossa. The height of the trial implant must be noted by drawing a horizontal mark on the stem. Final Stem was placed into the intramedullary canal following bone cement placement (PMMC) while maintaining 30-degree retroversion. Appropriate size head was then fixed over the stem. Greater and lesser tuberosities were reconstructed over the implant with the help of non-absorbable sutures.

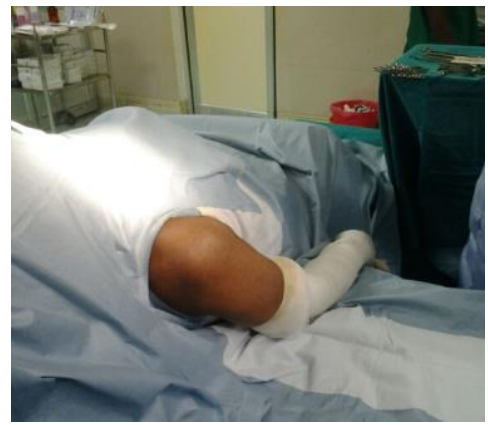

Fig 1: Beach chair position

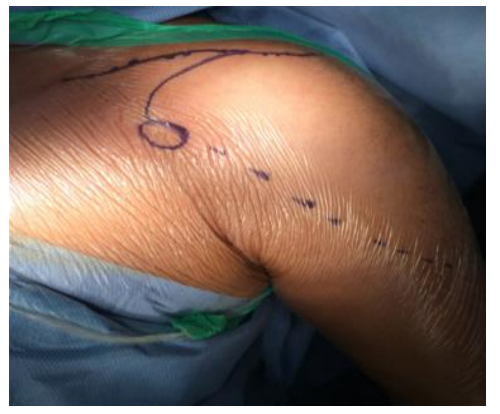

Fig 2: Deltopectoral approach

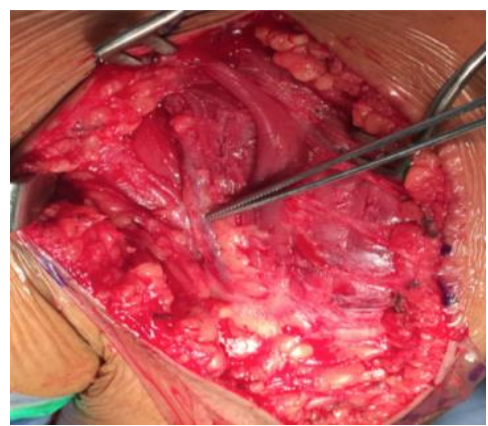

Fig 3: cephalic vein

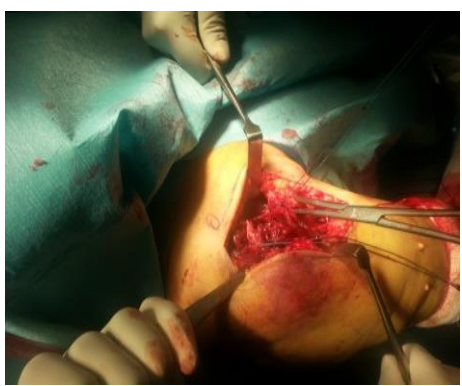

Fig 4: isolation of tuberosities and head retrieval

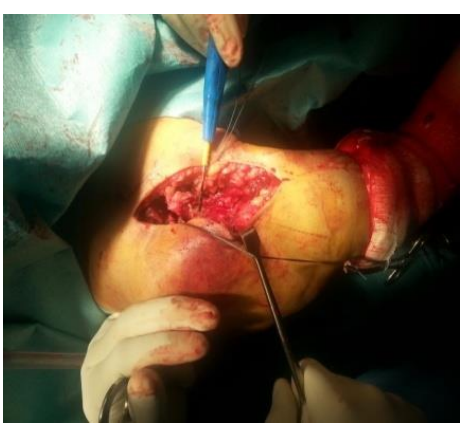

Fig 5: Bicipital groove, landmark for version 


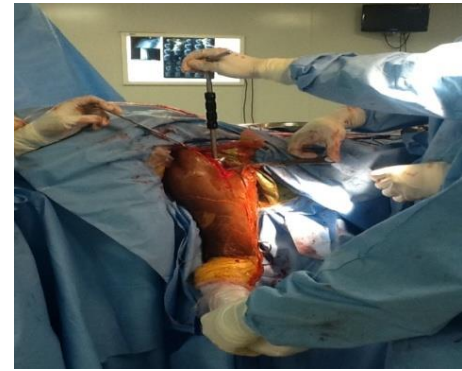

Fig 6: version parallel to forearm

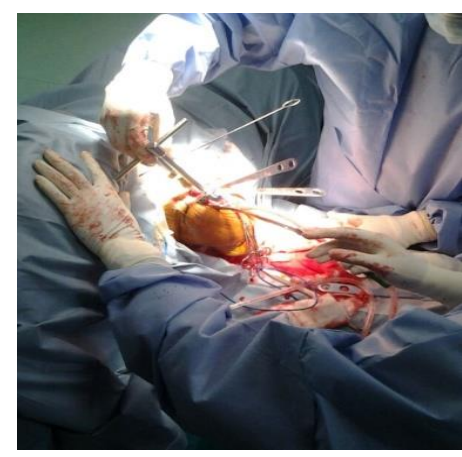

Fig 7: Role of guide for ersion
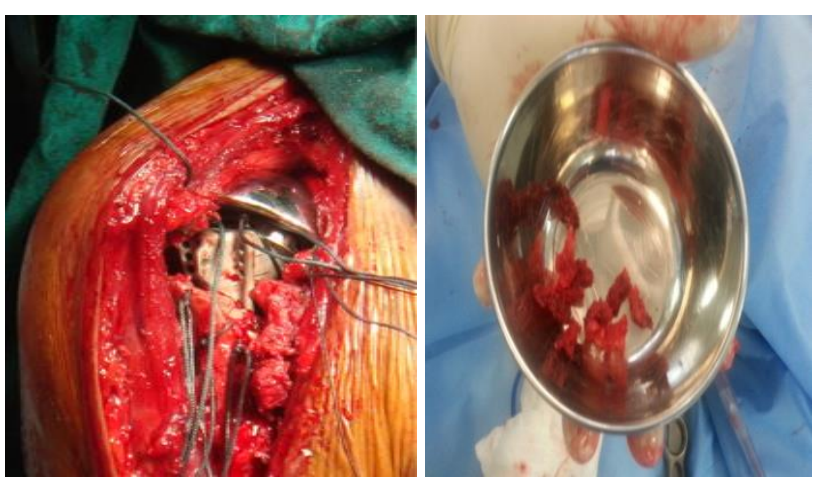

Fig 8, 9: tuberosity reconstruction

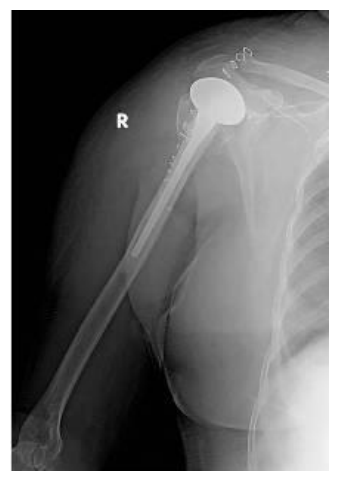

Fig 10: post-op x-ray

Post-operative care: Postoperatively, a shoulde immobiliser was used. Gravity assisted pendulum exercises were allowed on day 1. At 3 weeks, assisted forward elevation and supine external rotation and full elbow range-of-motion exercises were allowed for the next 6 weeks or longer (until adequate tuberosity healing can be appreciated on x-rays). At weeks 6 to 8 , stretching and strengthening of the shoulder with the help of a theraband was allowed under supervision. Daily home exercises were encouraged for at least 6 months. Follow-up of patients was done at six weeks, three months and six months following the surgery.

Statistical analysis: Data obtained was coded and entered into Microsoft Excel spreadsheet (Annexure III). The categorical data was expressed as rate, ratio and percentage. The continuous data was expressed as mean \pm S.D. Fisher's exact test was used to find the association between categorical data and paired ' $t$ ' test was used to compare the mean change in range of motion. A ' $p$ ' value of less than or equal to 0.05 at 95\% confidence interval was considered as statistically significant. The present hospital based retrospective study was done in the Department of Orthopaedics, IMS\&SUM HOSPITAL, Bhubaneswar. A total of 30 patients with four part proximal humerus fractures based on Neer's classification during the period of July 2015 to June 2019 were included in the study.

Table 1: Sex Distribution of study population

\begin{tabular}{|c|c|c|}
\hline \multirow{2}{*}{ Sex } & \multicolumn{2}{|c|}{ Distribution $(\mathbf{n = 3 0})$} \\
\cline { 2 - 3 } & Number & Percentage \\
\hline Male & 24 & 80 \\
\hline Female & 6 & 20 \\
\hline Total & 30 & 100.00 \\
\hline
\end{tabular}

Table 2: Age Distribution of study population

\begin{tabular}{|c|c|c|}
\hline \multirow{2}{*}{ Age group (Years) } & \multicolumn{2}{|c|}{ Distribution (n=30) } \\
\cline { 2 - 3 } & Number & Percentage \\
\hline 50 to 70 & 27 & 90 \\
\hline$>70$ & 3 & 10 \\
\hline Total & 30 & 100.00 \\
\hline
\end{tabular}

Table 3: Mode of Injury

\begin{tabular}{|c|c|c|}
\hline \multirow{2}{*}{ Mode of Injury } & \multicolumn{2}{|c|}{ Distribution $(\mathbf{n}=\mathbf{3 0})$} \\
\cline { 2 - 3 } & Number & Percentage \\
\hline Self-fall & 9 & 30 \\
\hline RTA & 21 & 70 \\
\hline Total & 30 & 100.00 \\
\hline
\end{tabular}

Table 4: side of fracture

\begin{tabular}{|c|c|c|}
\hline \multirow{2}{*}{ Side } & \multicolumn{2}{|c|}{ Distribution $(\mathbf{n = 3 0})$} \\
\cline { 2 - 3 } & Number & Percentage \\
\hline Left & 6 & 20 \\
\hline Right & 24 & 80 \\
\hline Total & 30 & 100.00 \\
\hline
\end{tabular}

Table 5: constant Murley shoulder score (CMS)

\begin{tabular}{|c|c|c|}
\hline \multirow{2}{*}{ CMS } & \multicolumn{2}{|c|}{ Distribution $(\mathbf{n = 3 0})$} \\
\cline { 2 - 3 } & Number & Percentage \\
\hline Excellent & 18 & 60 \\
\hline Good & 6 & 20 \\
\hline Fair & 5 & 16.66 \\
\hline Poor & 1 & 3.33 \\
\hline Total & 30 & 100.00 \\
\hline
\end{tabular}

Table 6: Comparison of range of movements

\begin{tabular}{|c|c|c|c|c|c|c|c|c|c|}
\hline \multirow{2}{*}{ Variables } & \multicolumn{2}{|c|}{ 6 weeks } & \multicolumn{2}{c|}{ 3 months } & \multicolumn{2}{c|}{ 6 months } & \multicolumn{2}{c|}{ Mean increase } & \multirow{2}{*}{ p value } \\
\cline { 2 - 10 } & Mean & SD & Mean & SD & Mean & SD & Mean & SD & \\
\hline Flexion & 59.50 & 16.38 & 76.00 & 15.69 & 92.00 & 17.04 & 32.50 & 12.93 & $<0.001$ \\
\hline Extension & 25.00 & 8.27 & 34.50 & 6.05 & 43.00 & 6.57 & 18.00 & 5.23 & 0.019 \\
\hline
\end{tabular}




\begin{tabular}{|c|c|c|c|c|c|c|c|c|c|}
\hline Abduction & 63.00 & 13.80 & 80.00 & 14.87 & 94.50 & 15.72 & 31.50 & 13.87 & $<0.001$ \\
\hline Adduction & 25.50 & 6.86 & 35.50 & 7.59 & 43.50 & 6.71 & 18.00 & 6.16 & 0.007 \\
\hline External rotation & 31.50 & 7.45 & 42.00 & 8.34 & 51.50 & 9.33 & 20.00 & 6.49 & $<0.001$ \\
\hline Internal rotation & 33.00 & 8.01 & 44.50 & 8.87 & 57.00 & 11.74 & 24.00 & 10.46 & 0.012 \\
\hline
\end{tabular}

\section{Discussion}

The fractures of proximal humerus accounts for 4 to $5 \%$ of all fractures; $11 \%$ of these entail 3- or 4-part fragments. For comminuted fractures, non-opeative treatment gives poor results, whereas internal fixation yields poor results in osteoporotic patients. Hemiarthroplasty for 3- and 4-part proximal humeral fractures achieves varying results. Recent adances in surgical technique and the use of modern prostheses has enabled better functional outcomes. Restoration of humeral length and correct positioning of the tuberosities are the most important predictors of successful outcome. The present study evaluated the efficacy of functional outcome of shoulder hemi replacement in patients diagnosed as four part fracture and four part fracture dislocation in elderly patients. A total of 30 elderly (age $\geq 60$ years) patients with four part proximal humerus fractures based on Neer's classification underwent shoulder hemi replacement. These patients were evaluated for functional outcome using constant shoulder score. The patients age ranged from 60 to 86 years and $90 \%$ of the patients were aged between 60 to 70 years and $10 \%$ were aged $>70$ years. The mean age was $65.35 \pm 5.58$ years. It is reported that, approximately $70 \%$ of fractures occurring in women. However, in the current study male preponderance was noted as $80 \%$ of the patients were males and the male to female ratio was $4: 1$. In the present study most of the patients had history of RTA (70\%) followed by fall (30\%). Previous studies have also reported that, the proximal humeral fractures are usually low-energy osteoporotic injuries in elderly. In the present study pain was present in all the patients (100\%) at six weeks follow up and resolved in $24(80 \%)$ patients at three months follow up and persisted in $6(20 \%)$ of the patients. Among them, pain was resolved in $5(16.66 \%)$ patients at six months follow up while in $1(3.33 \%)$ patients the pain persisted at six month follow up. The complications of pain observed in the present study were comparable with a study by Kralinger et al. in 2004 who reported moderate to severe pain in 35 out of $167(21 \%)$ patients with mean age of 70 years. Similar pain pattern was also reported by Demirhan et al. in 2003. In contrast Christoforakis JJ, et al. in 2004 reported pain in as low as 1 out of 25 patients $(3.8 \%)$ patients with mean age of 70 years while an earlier study by Zyto K, et al. in 1998 reported pain in as high as 9 out of 27 (33\%) patients with mean age of 71 years. Complications after humeral head replacement include infections, wound problems, nerve injuries, intra-operative fractures, instability, non-union and migration of the tuberosities, rotator cuff tears, component malposition and loosening, ossification, and stiffness. In this study the complications of proximal migration of GT and stiffness were noted in 1 patient each $(3.33 \%$ each) at three months follow up and these complications persisted till six months follow up. In patient with GT migration, the patients was advised surgery for reattachment and patient was non compliant while one patient who had stiffness, he was advised strict regimen of physiotherapy to improve his movement. The complications of tuberosity were reported in several other studies varies widely from $10 \%$ to $50 \%$. Least frequency of complications is reported by Zyto et al. where 3 out of 27 patients $(11.11 \%)$ had greater tuberosity displacement whereas Mighel et al. noted 16 out of 72 patients $(22.22 \%)$ with tuberosity complications, Kralingher et al. found these complications in 77 out of 167 patients (46\%) and Boilcau et al. in 2002 encountered tuberosity complications in as high as $50 \%$ of the patients. However, in the present study only one patient had proximal migration of GT $(3.33 \%)$, which was substantially low compared to other studies reported in the literature. With regard to the stiffness noted in one patient $(3.33 \%)$, studies reporting stiffness as a complication of hemi arthroplasty in the literature could not be found, hence this could not be commented upon. In the present study there was steady increase in mean range of movements pertaining to flexion, extension, abduction, adduction, external rotation and internal rotation from six weeks follow up three months and further increase was noted at six months follow up. The increase in mean range of motion observed at six months follow up compared to six weeks follow up was statistically significant (Table 6 in Results section) $(\mathrm{p}<0.050)$. The mean active forward flexion at six months follow up was noted as $92 \pm$ 17.04 and external rotation as $51.5 \pm 9.33$. The mean active forward flexion noted in the present study was comparable with several other studies by Prakash et al., Boilcau et al. and Goldman et al. but mean external rotation was high in the present study compared to these studies. A recent study by Babhulkar A. et al. from Pune India in 2011 on patients aged from 27 to 83 years reported that, at the final follow-up, the mean maximum abduction was $111^{\circ}\left(\mathrm{SD}, 47^{\circ}\right.$; range, $30^{\circ}-$ $180^{\circ}$ ), and the mean maximum forward flexion was $143^{\circ}$ (SD, $41^{\circ}$; range, $45^{\circ}-180^{\circ}$ ) which was $94.50 \pm 15.72$ and $92 \pm$ 17.04 in the present study respectively. However, authors did not report the pattern of increase in the range of motion. The difference in variation can be explained by the lower mean age (56 years) in the study by Babhulkar A. et al. In the present study final outcome at six months was assessed using constant shoulder score. The constant shoulder score at six month follow up ranged between 25 to 93 and mean score were found to be $71.05 \pm 18.50$ suggestive of good outcome in study population. Though the mean constant scores observed in the present study were high compared to studies by Zyto et al., Christoforakis et al., Kralinger et al., Becker et al., Boileau et al., Solberg et al. and Gronhagen et al., the method of final functional outcome differed as the latter studies evaluated functional outcome based on Constant Murley score, hence the direct comparison was not possible.

Hemiarthroplasty is an excellent treatment modality for comminuted proximal humeral fractures with good pain relief, but functional limitation may persist. Patient age, gender, injury to surgery interval, rehabilitation time, and condition of the rotator cuff affect functional outcome, as does anatomic union of the tuberosities and rotator cuff. In the present study, based on constant shoulder score, functional outcome was excellent in $18(60 \%)$ patients, good in $6(20 \%)$ patients fair in $5(16.66 \%)$ patients and poor outcome in $1(3.33 \%)$ patients. Further the outcome was independent of gender, side affected and mechanism of injury $(p>0.050)$. Overall the present study showed that, shoulder hemi arthroplasty in elderly patients diagnosed with four part fracture and dislocation of proximal humerus is efficacious in terms of favorable functional outcome with lower rate of complications. 


\section{Conclusion}

It may be concluded from the current study that, shoulder hemi replacement in elderly patients diagnosed to have with four part fracture and dislocation of proximal humerus is efficacious and results in favourable functional outcome as measured by constant shoulder score. Further this procedure provides excellent range of movements at shoulder joint with lower rate of complications especially pain and shoulder stability.

\section{References}

1. Green A, Norris T. Proximal humerus fractures and fracture dislocations. In: Browner B, Jupiter J, Levine A, Trafton P, editors. Skeletal trauma: basic science, management and reconstruction. 3. Philadelphia: Saunders. 2003, 1532-1624.

2. Court-Brown CM, Garg A, Mc-Queen MM. The epidemiology of proximal humeral fractures. Acta Orthop Scand. 2001; 72(4):365-371. DOI: $10.1080 / 000164701753542023$

3. Harrison AK, Gruson KI, Zmistowski B et al. Intermediate outcomes following percutaneous fixation of proximal humeral fractures. J Bone Joint Surg Am. 2012; 94(13):1223-1228. DOI: 10.2106/JBJS.J.01371

4. Spross C, Platz A, Rufibach K et al. The PHILOS plate for proximal humeral fractures-risk factors for complications at one year. J Trauma Acute Care Surg. 2012; 72(3):783-792. DOI: 97/TA.0b013e31822c1b5b.

5. Connor PM, Flatow EL. Complications of internal fixation of proximal humeral fractures. Instr Course Lect. 1997; 46:25-37.

6. Gerber C, Werner CM, Vienne P. Internal fixation of complex fractures of the proximal humerus. J Bone Joint Surg Br. 2004; 86(6):848-855. DOI: 10.1302/0301620X.86B6.14577.

7. Brorson S, Olsen BS, Frich LH. et al. BMC Surgeons agree more on treatment recommendations than on classification of proximal humerus fractures. Musculoskelet Discord. 2012; 13(1):114. DOI: 10.1186/1471-2474-13-114.

8. Zyto K. Non-operative treatment of comminuted fractures of the proximal humerus in elderly patients. Injury. 1998; 29(5):349-352. DOI: 10.1016/S0020-1383(97)00211-8.

9. Neviaser AS, Hettrich CM, Dines JS, Lorich DG. Rate of avascular necrosis following proximal humerus fractures treated with a lateral locking plate and endosteal implant. Arch Orthop Trauma Surg. 2011; 131(12):16171622. DOI: 10.1007/s00402-011-1366-6.

10. Frankle MA, Chacon-Balados A, Cuff D. Reverse shoulder prosthesis for acute and chronic fractures. In: Dines DM, Laurencin CT, Williams GR, editors. Arthritis and Arthroplasty: The Shoulder. Philadelphia: PA, Saunders; 2009, 218-231.

11. Olerud P, Ahrengart L, Ponzer S, Saving J, Tidermark J. Hemiarthroplasty versus nonoperative treatment of displaced 4-part proximal humeral fractures in elderly patients: a randomized controlled trial. J Shoulder Elbow Surg. 2011; 20(7):1025-1033. DOI: 10.1016/j.jse.2011.04.016.

12. Thanasas C, Kontakis G, Angoules A, Limb D, Giannoudis P. Treatment of proximal humerus fractures with locking plates: a systematic review. J Shoulder
Elbow Surg. 2009; 18(6):837-844. DOI: 10.1016/j.jse.2009.06.004.

13. Liu J, Li SH, Cai ZD et al. Outcomes, and factors affecting outcomes, following shoulder hemiarthroplasty for proximal humeral fracture repair. J Orthop Sci. 2011; 16(5):565-572. DOI: 10.1007/s00776-011-0113-8.

14. Murachovsky J, Ikemoto RY, Nas-cimento LG et al. Pectoralis major tendon reference (PMT): a new method for accurate restora- tion of humeral length with hemiarthroplasty for fracture. J Shoulder Elbow Surg. 2006; 15(6):675-678. DOI: 10.1016/j.jse.2005.12.011.

15. Sirveaux F, Navez G, Roche O, Molé D, Williams MD. Reverse prosthesis for proximal humerus fracture, technique and results. Tech Shoulder Elbow Surg. 2008; 9:15-22. DOI: 10.1097/BTE.0b013e31815dca3c. 